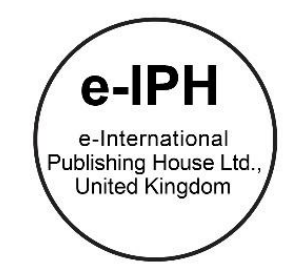

\title{
Investigating Meaning-making Process in Design Collaboration Activities: Designers interaction with objects
}

\author{
Abu Ali ${ }^{1}$, Andre Liem², Siti Salwa Isa ${ }^{1}$, Siti Suriawati Isa ${ }^{3}$ \\ ${ }^{1}$ Faculty of Arts \& Design, Universiti Teknologi MARA, 40450 Shah Alam, Selangor, Malaysia \\ 2 Department of Design, Norwegian University of Science and Technology, Kolbjørn Hejes vei 2B, Trondhiem, Norway \\ ${ }^{3}$ Department of Recreation \& Ecotourism, Faculty of Forestry, Universiti Putra Malaysia, 43400 Serdang, Selangor, Malaysia \\ abuali@uitm.edu.my; andre.liem@ntnu.no; sitisalwa@ uitm.edu.my; ssuria4@upm.edu.my \\ Tel: +60134017304
}

\begin{abstract}
Various ways of accessing the meaning-making process in design activity have been explored in many fields of user-centred design, participatory design and human product experienced. However, designer collaboration activities in meaning findings have rarely been studied or reported. Therefore, this research investigates the influence of designers' collaboration on designers' thinking in creating meaning in the design process and the design elements that influence their making. It can be concluded that experience and a more active observation with an object in design practice contribute to the better idea in the meaning-making process.
\end{abstract}

Keywords: meaning-making, design thinking, the principle of design

eISSN: 2398-4287@ 2020. The Authors. Published for AMER ABRA CE-Bsby e-International Publishing House, Ltd., UK. This is an open access article under the CC BYNC-ND license (http://creativecommons.org/licenses/by-nc-nd/4.0). Peer-review under responsibility of AMER (Association of Malaysian Environment-Behaviour Researchers), ABRA (Association of Behavioural Researchers on Asians) and CE-Bs (Centre for Environment-Behaviour Studies), Faculty of Architecture, Planning \& Surveying, Universiti Teknologi MARA, Malaysia.

DOI: https://doi.org/10.21834/ebpj.v5iSI3.2540

\subsection{Introduction}

Designs can be characterised as the realisation of communication that concern with meaning. They are ranked based on intention, construction, and reception or reconstruction of meaning. According to Press, \& Cooper, (2017); and Kazmierczak, (2003) designs are the activities that direct the process and correspond to focus on receiving the meaning, to shift the design paradigm and move from the preoccupation with designing an object to particular uses. Those activities enable the designer to reconstruct the intended meaning. To explore that, this research establishes the practical design workshop to search for meaning based on design activities. According to Tversky, (1999) sketches transmit abstract ideas symbolically, using elements and spatial relations on paper to determine/symbolise precise intangible elements and relationship. Besides, this research also explores the meaning of how participants express their idea based on what they observe, experience, and translate to design through sketching and clay building mock-up process (Press, \& Cooper, (2017); Zahedi, et al 2012). It is often argued that when design practitioners work in designing process with others, they frequently deal with conflict situations. Hence, this workshop also investigates factors of communication that might also contribute to generating ideas in the design process or dealing with conflict. The method of this study is using sketching and clay as a tool to transmit and transform the idea from objects to seater. Therefore, this workshop aims to find out how participants create "meaningmaking" in the design process and how they transmit and transform meaning using the medium such as paper, pencil, and clay. The

eISSN: 2398-4287@ 2020. The Authors. Published for AMER ABRA cE-Bsby e-International Publishing House, Ltd., UK. This is an open access article under the CC BYNC-ND license (http://creativecommons.org/licenses/by-nc-nd/4.0). Peer-review under responsibility of AMER (Association of Malaysian Environment-Behaviour Researchers), ABRA (Association of Behavioural Researchers on Asians) and cE-Bs (Centre for Environment-Behaviour Studies), Faculty of Architecture, Planning \& Surveying, Universiti Teknologi MARA, Malaysia.

DOI: https://doi.org/10.21834/ebpj.v5iSI3.2540 
research questions formulated for this study are: 1) How does a designer's collaboration influence designers thinking in creating meaning in the design process? 2) What type of design elements do designers use to express their meaning in the design process?

\subsection{Method}

There were 8 participants participated in this two-hour workshop. The participants were divided into four groups consisting of two participants each. The participants were from various backgrounds, including design practitioners, a professor, a post-doctoral student, a doctoral candidate, and a master student in the design fields. There were five females, and three males took part in this workshop. The participants were from Chalmers University of Technology, Konstfack, University College of Art, Craft and Design, Linkoping University, Parsa Kamehkhosh Art \& Design Studio, Swedish Institute for Computer Science (SIGS), and Lund, University, Sweden. The workshop focused on designing "objects for sitting" based on four random objects. The workshop was structured in four stages, beginning with short presentations from the facilitator. Then, it was followed by specific activities where the participants observed and experienced four random objects. The third stage was sketching activities, where the participants had to explore ideas and transform them through $2 \mathrm{D}$ sketchers. For the final stage, all of the participants had to produce one last 3D mock-up design by clay before moving to the next task. The participants had to complete three different objects in this workshop. The facilitator observed and recorded all the activities from the beginning stage, until the end of the design task and gathered all the data for the analysis stage. During the design process, the facilitator acted as a timekeeper to remind the participants at every stage of the design tasks. The participants had to complete each of the design tasks within 30 minutes, and there were approximately two hours to complete all the three design tasks, including the design briefing at the previous stage by the facilitator. In this study, the author used the design task approach to observe the meaning created in the design process. In this task, sketching and mock-ups were used as methods to transform the idea. This study used random objects to provoke the designers to design an object for sitting. There were several objects randomly picked for this study, and the objects were (Figure 1); (i) Object A- a box and carpets, (ii) Object B - a bunch of rope and square basket (iii) Object $C$ - boxboard paper that ties in a cylinder shape and several white containers, and (iv) Object D several squares and cube polystyrenes. The design brief for this task was "Object for sitting", and this project aimed to study how designers create meaning-making in the design process.

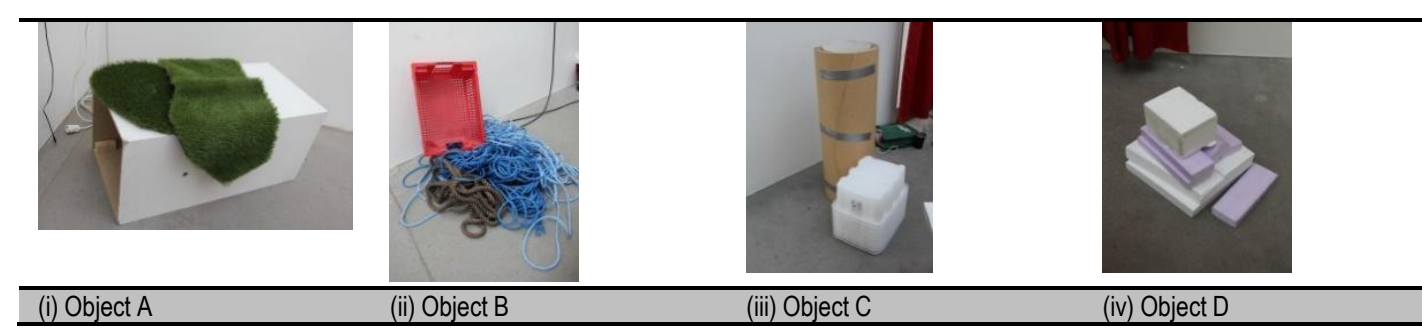

Fig. 1. Four random objects for the "object for sitting" design task

All of the participants were divided into four groups, Participants 1 and 2 started with objects $A, D$ and $C$, participants 3 and 4 with objects $B, A$ and D, participant 5 and 6 with objects $C, B, A$ and participants 7 and 8 with objects $D, C$ and B. All participants had managed to complete each of the design tasks in approximately thirty minutes and completed all three different objects within one and half hours to two hours. In the data collection, the author found that there were 22 sketches and 24 mock-ups altogether. In the two hours design task, all the participants had to come out with at least three 2D sketches and three 3D mock-ups for their final designs. In the room setting, the participants needed to move to another task in anti-clockwise. As for the design process, all the participants had to stay together with their partners and complete with three stages. At the first stage, the participants had to observe and experience with random objects before proceeding to the second stage. The second stage involved the sketching process, and the participant had to choose the final design to build the 3D mock-ups. Overall, the entire participant had to complete three different tasks of objects and deliver three 2D sketches and three final 3D mock-ups. The facilitator observed and recorded all tasks from the beginning where the participants experienced the objects until the end of the design tasks.

\subsection{Results and Discussion}

\subsection{Reflection from Participant 1.}

Participant 1 completed all tasks with several sketches and three mock-ups. She completed the tasks after several discussions with Participant 2, which led to the transformation of the meaning from several activities into conceptions (figure2).

\subsubsection{Participant's experience with objects}

At this point, she captured the physical appearances of the objects and observed her partner in interpreting the intangible meaning to uncover insight. To deeply understand the user feeling, she got engaged with her partner by discussing and interacting with the 
objects. To understand the experience, she experimented and interacted herself with the object to discover the emotions and memorising the feeling to recognise the user behaviour.

\subsubsection{Participant defines the meaning}

During this session, she transformed the first experience and observation of user needs to "meaning" into several fuzzy conceptions. At this stage, she defined her final conception with a design solution after discovering the insight. As a solution, she decided that the reclining object was the best solution for Object 1, bench for Object 2 and geometrical for Object 3 .

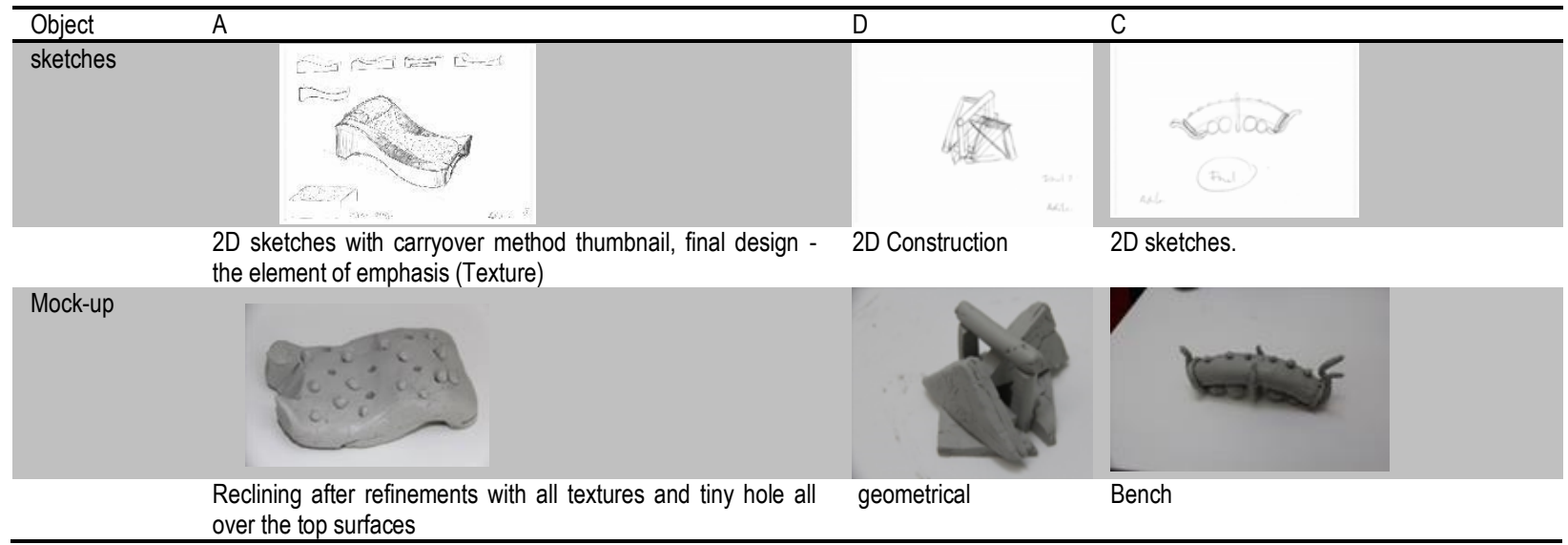

Fig. 2. Reflection on final design participant 1.

\subsection{Reflection from Participant 2.}

Participant 2 managed to complete three sets of 2D sketches and 3D final mock-ups. Participant 2 actively explored and discussed with her partner (participant 1) to gain a new idea in the design task. As mentioned earlier, they were involved with many activities together, but they came out with separated individual designs (figure 3).

\subsubsection{Participant's experience with objects}

Participant 2 observed and memorised her partner's behaviour in interacting with the objects. Before carrying out the same activity, participant 2 indirectly acquired some insight and provided the corresponding solution to the objects she had observed and experienced earlier.

\subsubsection{Participant defines the meaning}

Participant 2 transmitted the meaning from the experienced and the observation into the uncertain conception. After initiated the insight, she distinguished the solution in the statement of her design. She derived a radical organic design in her first design task. Surprisingly, there were similarities between the conception of reclining object for sitting with her partner (participant 1) but in a different design. However, the design was a different concept for both designers in their second and third conceptions.

\begin{tabular}{llll}
\hline Object & A & C & D \\
\hline sketches & 2D sketches with carryover method thumbnail, & A geometrical 3D Sketches & $\begin{array}{c}\text { Description of the character to show } \\
\text { funny and joyful. }\end{array}$ \\
Mock-up & $\begin{array}{l}\text { A reclining with radical uncertain conception. A geometrical structure seating } \\
\text { Refinement at the upper structure-dramatic. }\end{array}$ & $\begin{array}{l}\text { Children playground seating object } \\
\text { objects with radical balance }\end{array}$ \\
\hline
\end{tabular}

Fig. 3. Reflection on final design participant 2.

\subsection{Reflection from Participant 3.}

Participant 3 started with experiencing and observing Object B. He only achieved two sets of sketches, but with three mock-ups. He did not interact much with his partner at almost all stages of the design task. He experimented with the objects by himself and 
transcribed the insight through his experience while interacting with the objects. Participant 3 used his sense while interacting with objects such as touching, tasting, and focused on sitting activity (figure 4).

\subsubsection{Participant's experience with objects and define the meaning}

Participant 3 outlined his insight in a different approach. He used himself as a user to solve the problem. He used his sense in various objects by himself. Since the sense is tacit, it is often taken for granted and concerned with familiar, common, and unproblematic surroundings. The author realised that participant 3 struggled to encapsulate his insight while interacted with unfamiliar surrounding such as Objects B. He looked more confident and comfortable to generate his insight with Object A and D after the experience with the objects. At this stage, he indicated stool as his overall conceptions.

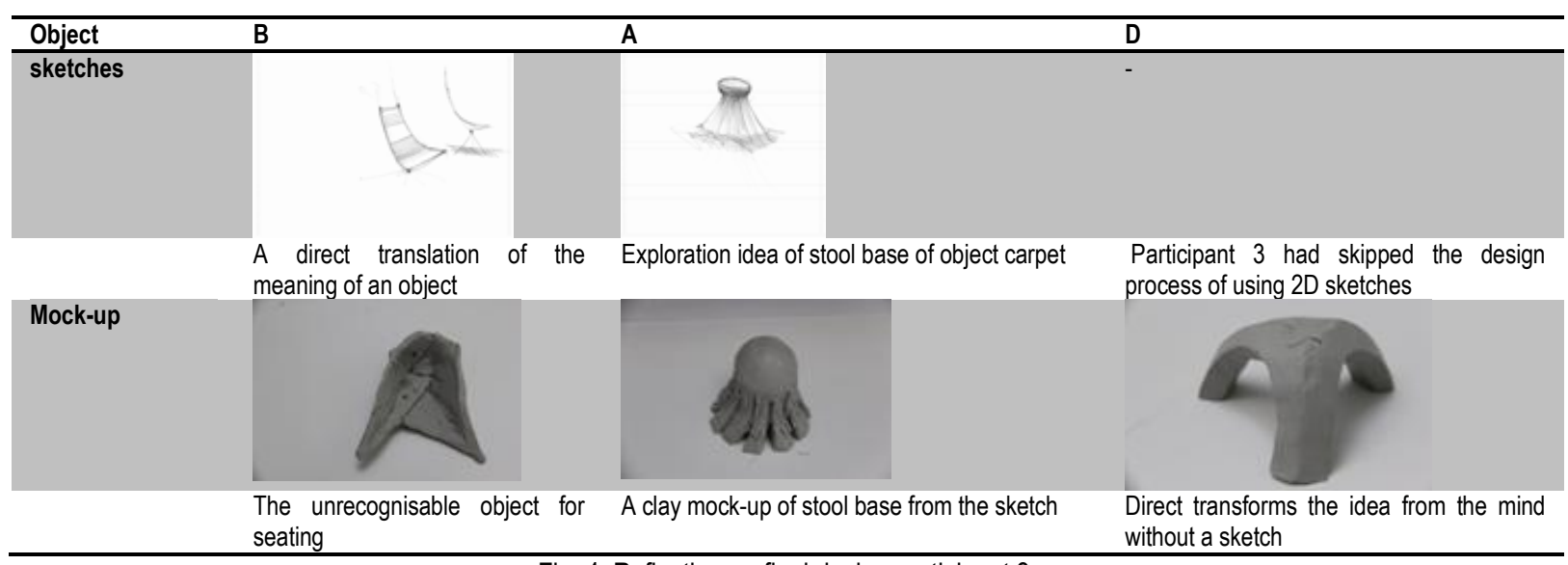

Fig. 4. Reflection on final design participant 3.

\subsection{Reflection from Participant 4}

Participant 4 managed to complete only two sets of 2D sketches and 3D mock-ups at the end of the design task. The same goes to participant 2, where he did not interact much with his partner in the design process. Apart from using his senses in interacting the objects, he used the previous experiences as a guideline in his conception (figure 5)

\subsubsection{Participant's experience with objects}

Started with Object $B$, he used his sense to experience and understand the objects. He used himself as a pointer of seeking the inspirations to uncover the insight, which in some extent, had influenced all of his designs. As a result, he transformed his meaning from what he observed and experienced the conceptions that are related to nature.

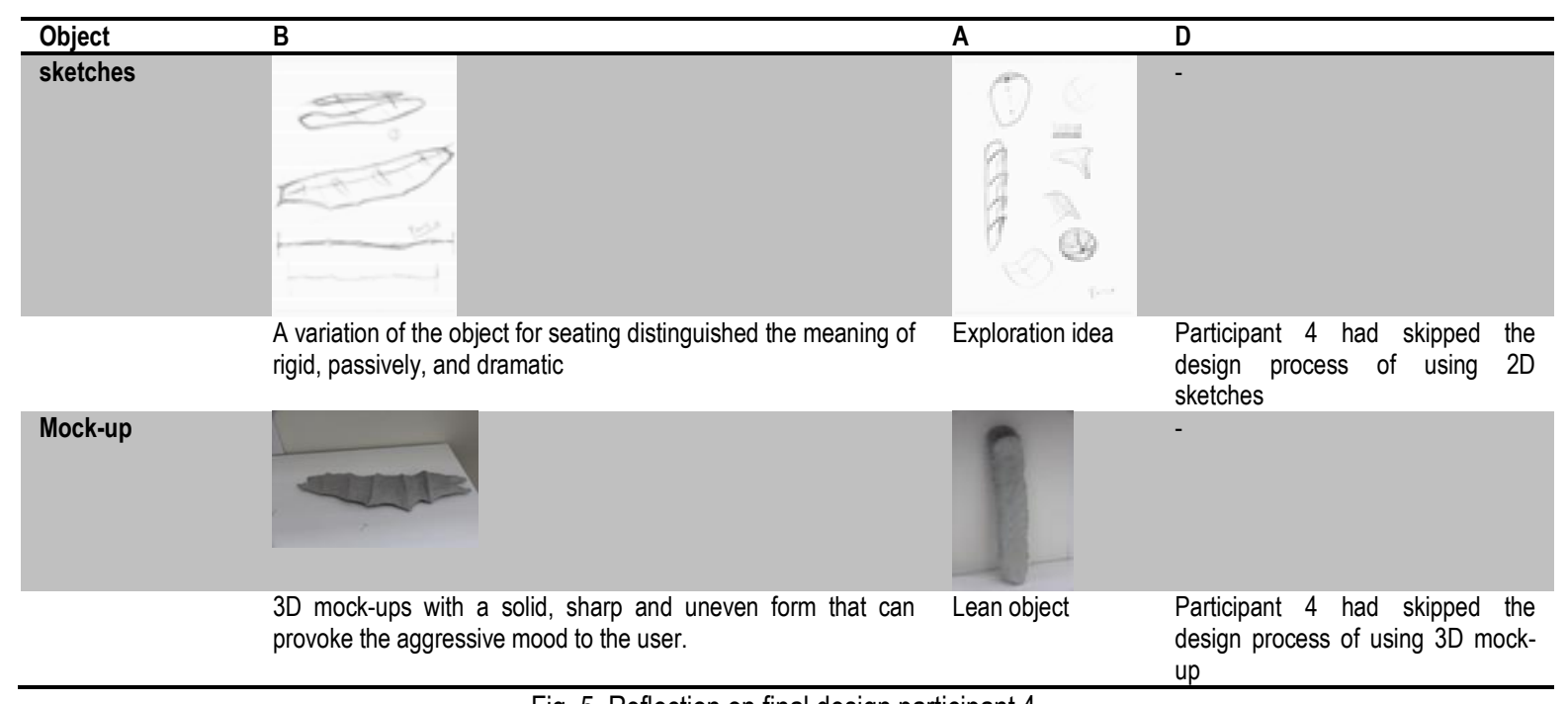

Fig. 5. Reflection on final design participant 4.

\subsection{Reflection from Participant 5 and 6.}

There was an interesting finding upon this discussion about participants 5 and 6 . The author found that both of the participants initiated to working as a design team in this task. As compared to participants 1 and 2, they only shared information when directly involved in some specific activities, but came out with individual design solutions, except for design 1 . The interesting part about these two participants 5 and 6 is, they acted as a design team and did the exercise together and shared the same results and findings 
(figure 6).

\subsubsection{Participant's experience with objects}

For the experience with objects stages, both of them started with Object $\mathrm{C}$. They managed to arrange with several compositions and came out with a simple solution for the design. For Object $B$, they aggressively used several approaches to interact with the objects to find out possible solutions. Similar to other participants, Object B constituted the most difficult and challenging objects to experience with. For example, they used several methods while interacting with objects such as pooling and tying up the partner in their quest to find design solutions (see figure 6). However, with Object A, participant 5 also acted as a user and interacted with the objects to deeply understand the user's feeling. They shared data information and drew out the design statement based on the observations and experiences.

\subsubsection{Participant defines the meaning}

To uncover the unforeseen problem, they used several methods to understand the meaning of experience and observation of the fuzzy conceptions. They understood the several arrangements of design principles; hence, as a result, they managed to produce the best solution for their final design. As clearly shown in their design from Object $\mathrm{C}$; they used several arrangements of the objects to produce a multi-purpose object for sitting. This design can not only be used for sitting purposes but also as a resting object to support user head and shoulder. Similar to Object B and A, active investigation and understanding of the characteristic of the objects enabled them to distinguish the meaning to several conceptions such as the multi-purpose rope and multi-purpose chair.

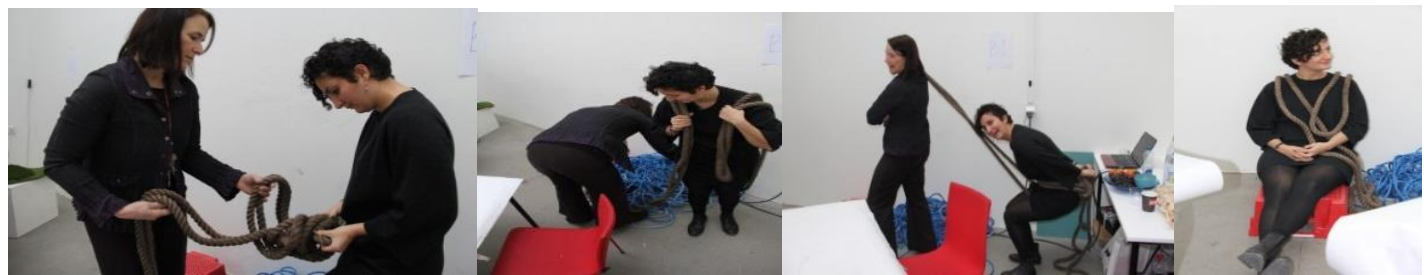

Fig. 6. They use several methods while interacting with objects such as pooled and tied up the partner.

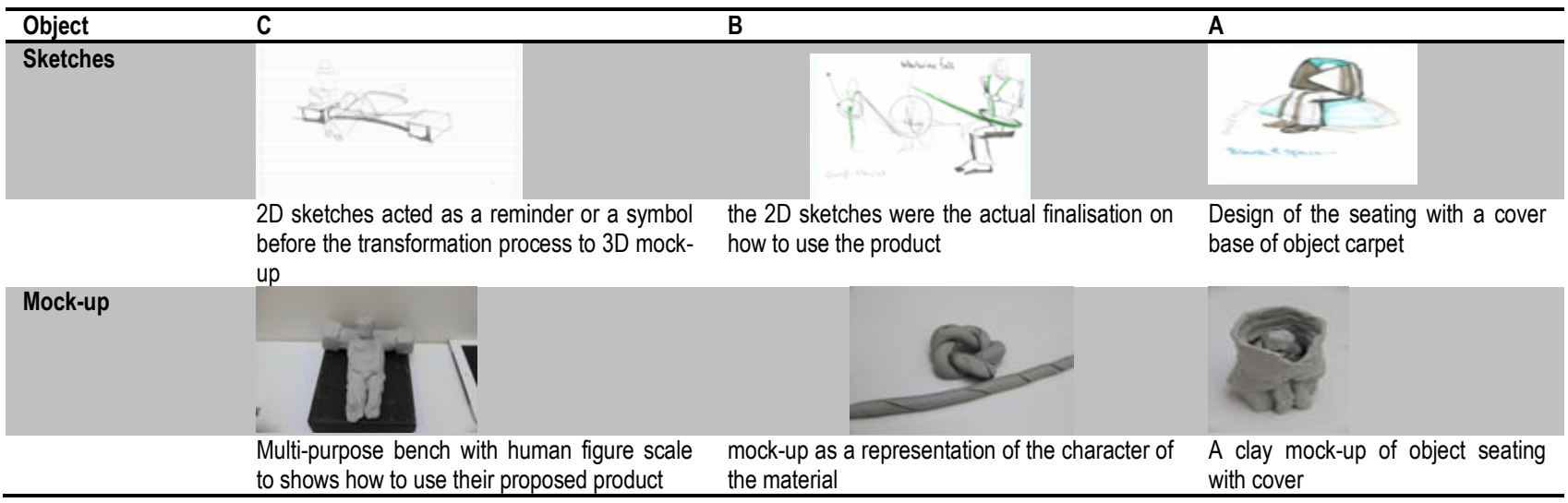

Fig. 7. Reflection on final design participant $5 \& 6$.

\subsection{Reflection from Participant 7.}

Participant 7, managed to complete three sets of 2D sketches, and unexpectedly she came out with four mock-ups in this task. Overall, she was just like any other participants, beginning with observation and interaction with the objects. She had shared her opinions with the fellow group in experimenting the objects, and the interesting part about her was she seemed more focused on mock-ups building in the design process (figure 8 ).

\subsubsection{Participant's experience with objects}

Participant 7 and 8 started with Object $D$ with a small discussion in front of the objects. After a while, she observed her partner rearranged the objects as per their discussion earlier. She looked out for every single arrangement and sometimes gave an opinion and helped him to compose the objects. The arrangement took quite a time. After a few minutes, they left the objects and started the design process. According to Zahedi, M.et al (2012), when a designer works in the designing process with others, they frequently deal with a conflict situation. In this observation, the author believes that participant 7 , and 8 had a small conflict with the interpretation of the meaning of object D. She might have a different interpretation of the object. However, participant 8 agreed with the various thought of meaning that he captured during the arrangement process earlier. 


\subsubsection{Participant defines the meaning}

The author argues that she used her sense while interacting with the objects and analysed with her experience in her mental picture before transmitted her insight into the 2D sketches. She might use the result of the objects as a benchmark for her to explore with a wild idea. As a consequence, she transformed her meaning to 2D sketches with several artistic conceptions.

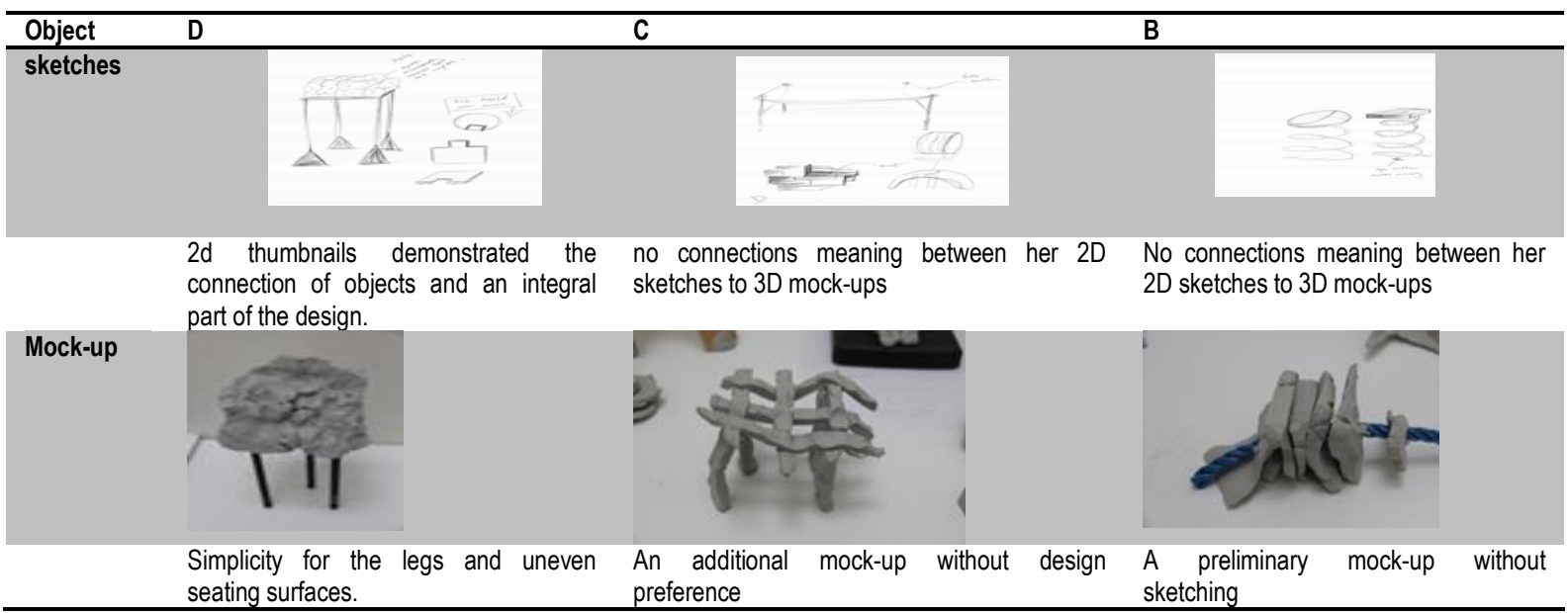

Fig. 8. Reflection on final design participant 7.

\subsection{Reflection from Participant 8.}

Participant 8 finished his entire task with three sets of 2D sketches, two mock-ups and one in completed 3D mock-up. He started his task experiencing and observing object $\mathrm{D}$ together with participant 7 . As mentioned earlier, he did not interact much with his partner. He experimented several arrangements of the objects and transcribed the insight through composing objects. Participant 8 used his design thinking by arranging the objects and transforming the meaning to his conception (figure 9).

\subsubsection{Participant defines the meaning}

Design thinking is a part of the designer knowing (Cross N. 2004), (Brown \& Wyatt, 2010) and brings knowledge to mind (Schon,1983). He captured the meaning by arranging and ordering with several approaches to understanding the character of the object. Once he has discovered the insight, he transformed the meaning from the arrangement and order of the 3D objects to his final conception. As a solution, he encapsulated the meaning from the arrangement and composted to bigger pictures. Instead of designing objects for sitting, he transformed the meaning of object for living. At this point, he expanded the concept of sitting on the object to the concept of living. The author believes through the concept of living, and the user did not only focus on sitting but on multiple operations like sleeping, cooking, hanging around, resting and reading the concept of living. The related concept that came around after the arrangement was an igloo. For Objects $\mathrm{C}$ and $\mathrm{B}$, participant 8 had almost directly transformed the meaning to $2 \mathrm{D}$ sketches.

\begin{tabular}{|c|c|c|c|}
\hline Object & D & C & B \\
\hline \multirow[t]{2}{*}{ sketches } & & & " \\
\hline & $\begin{array}{l}\text { transformed the meaning } \\
\text { throughout the 2D sketches with the } \\
\text { variation of 3D shape with the detail } \\
\text { indication and descriptions }\end{array}$ & $\begin{array}{l}\text { Exploration idea of } 2 \mathrm{D} \text { design with indications } \\
\text { and detailing }\end{array}$ & $\begin{array}{l}\text { Participant } 8 \text { applied mimicking methods } \\
\text { direct translation of-of Object } B \text { to } 2 D \\
\text { sketches }\end{array}$ \\
\hline \multicolumn{4}{|l|}{ Mock-up } \\
\hline & $\begin{array}{l}\text { Encapsulate the meaning of living } \\
\text { and randomly arranged the } 3 \mathrm{D} \\
\text { objects to become an igloo }\end{array}$ & $\begin{array}{l}\text { This 3D mock-up is considered as incomplete } \\
\text { design because there are some missing parts } \\
\text { compared to its 2D.- }\end{array}$ & $\begin{array}{l}\text { Participant } 8 \text { expanded the size of the objects } \\
\text { and added the human figure scales to the } \\
\text { final mock-up }\end{array}$ \\
\hline
\end{tabular}

Fig. 9. Reflection on final design participant 8. 


\subsection{Conclusion}

The reflections of experiencing and observation with the objects revealed the way participants transmit the meaning on their previous experience and background of their design practice to design process. The results proved that experiencing and observing an object more actively in the design practice will contribute to the better idea in the meaning-making process. The participatory design process is advantageous for creating new ideas in the design development process. The author also comprehends that this workshop has involved with participatory design practice. The participatory design manages to evoke creativity (Kanstrup \& Christiansen, 2006). The result shows that designers who were involved in participatory design would have involved with communicating with their partners. It contributes to creative problem solutions in the design process, as compared to the designer who works alone. Meanwhile in the design process, designers understand that organising the elements of design and arrangement with the principle of design will produce the best plan. Designers normally composed and arranged the visual design and captured in his or her mental picture before transmitting to the 2D sketches. At some point, 2D sketches only acted as a symbol of designer visual thinking before being transformed to 3D mock-ups. In the 3D mock-ups process, the mental picture will filter unsuitable elements and omit them from the design. This recognition will arrange which elements that can do or undo to the design. As the conclusion of this workshop, it is an approach to semiotic relations between perception and meaning construction. During this design process, communication is a fundamental way of understanding the need for people who will be the recipients of the design.

\section{References}

Ali, A., \& Liem, A. (2015). MEANING MAKING IN THE INTERSECTION BETWEEN SKETCHES AND 3D MOCK-UP. In DS 80-3 Proceedings of the 20th International Conference on Engineering Design (ICED 15) Vol 3: Organisation and Management, Milan, Italy, 27-30.07. 15 (pp. 397-406).

Brown, T., \& Wyatt, J. (2010). Design thinking for social innovation.

Cross, N. (2006). Designerly ways of knowing: Springer.

Dorst, K. (2011). The core of 'design thinking' and its application. Design Studies, 32(6), 521-532. doi:http://dx.doi.org/10.1016/j.destud.2011.07.006

Goldschmidt, G. (1991). The dialectics of sketching. Creativity research journal, 4(2), 123-143.

Goldschmidt, G. (1994). On visual design thinking: the vis kids of architecture. Design Studies, 15(2), 158-174.

Kanstrup, A. M., \& Christiansen, E. (2006). Selecting and evoking innovators: combining democracy and creativity. Paper presented at the Proceedings of the 4th Nordic conference on Human-computer interaction: changing roles.

Kazmierczak, E. T. (2003). Design as meaning-making: from making things to the design of thinking. Design Issues, 19(2), 45-59.

Lidwell, W., Holden, K., \& Butler, J. (2010). Universal principles of design revised and updated: 125 ways to enhance usability, influence perception, increase appeal, make better design decisions, and teach through design: Rockport Pub.

Nelson, H. G., \& Stolterman, E. (2003). The design way: Intentional change in an unpredictable world: Foundations and fundamentals of design competence: Educational Technology.

Press, M., \& Cooper, R. (2017). The design experience: the role of design and designers in the twenty-first century. Routledge.

Schon, D. A., \& Wiggins, G. (1992). Kinds of seeing and their functions in designing. Design Studies, 13(2), 135-156.

Schön, D. A. (1983). The reflective practitioner: How professionals think in action (Vol. 5126): Basic books

Suwa, M., Tversky, B., Gero, J., \& Purcell, T. (2001). Seeing into sketches: Regrouping parts encourages new interpretations. Paper presented at the Visual and spatial reasoning in design.

Tang, H., \& Gero, J. (2001). Sketches as affordances of meanings in the design process. JS Gero, B. Tversky and T. Purcell (eds), $271-282$.

Tversky, B. (1999). What does drawing reveal about thinking? Paper presented at the IN.

Yilmaz, S., \& Seifert, C. M. (2011). Creativity through design heuristics: A case study of expert product design. Design Studies, 32(4), 384-415.

Zahedi, M., Poldma, T., Baha, E., \& Haats, T. (2012a). Design Thinking and Aesthetic Meaning-Making: Interlaced Means to Engage in Collaborative KnowledgeBuilding.

Paper presented at the DS 71: Proceedings of NordDesign 2012, the 9th NordDesign conference, Aarlborg University, Denmark. 22-24.08. 2012.

Zahedi, M., Poldma, T., Baha, E., \& Haats, T. (2012b). Design Thinking and Aesthetic Meaning-Making:Interlaced Means to Engage in Collaborative KnowledgeBuilding. Paper presented at the NordDesign 2012, Aalborg, Denmark. 